\title{
SCN2A Pathogenic Variants- Important Causes of Epilepsy and Developmental Delay
}

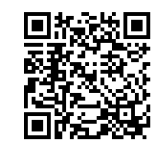

\author{
Ernesto Gonzalez-Giraldo* \\ Assistant Professor of Clinical Neurology and Pediatrics, University of California, San Francisco, USA
}

Submission: March 01, 2021; Published: March 09, 2021

*Corresponding author: Ernesto Gonzalez-Giraldo, Assistant Professor of Clinical Neurology and Pediatrics, University of California, San Francisco, USA

\section{Abstract}

Pathogenic variants in the SCN2A are an important cause of various neurological disorders including epilepsy, epileptic encephalopathies, autism, and other neurodevelopmental and neurological issues. Its diagnosis carries therapeutic and prognostic implications and should be sought in patients with evidence of epileptic encephalopathy.

Keywords: Neurological disorders; Autism; Epilepsy; Sodium channel; Antiseizure

\section{Introduction}

The SCN2A gene produces the major alpha subunit (Nav1.2) of the voltage gated sodium channel that plays an important role in the production and transmission of action potentials in excitatory neurons [1]. February $24^{\text {th }}$ marks the international SCN2A awareness day, aptly chosen gene's locus in chromosome 2q24.3. This brief review aims to expand awareness of this important cause of epilepsy, epileptic encephalopathy, autism, and other neurodevelopmental and neurological disorders [1].

Pathogenic variants in the SCN2A gene lead to a wide spectrum of neurological disorders that include benign familial neonatal-infantile seizures, epilepsy of infancy with migrating focal seizures, epileptic encephalopathies (Ohtahara syndrome, West syndrome, Lennox-Gastaut syndrome), and autism spectrum disorder [2]. In patients with less phenotypically severe disease there is a higher proportion of patients with inherited variants, whereas de novo variants are more likely to have a more severe phenotype [3].

In a study of 71 patients with pathogenic variants in the SCN2A gene, Wolff et al found three distinct phenotypic groups. One group had a phenotype consistent with early infantile epilepsy with onset before 3 months of age, typically with missense variants and gain-of-function effects on the sodium channel. A second group with epilepsy onset after 3 months of age, truncations splice site mutations, or missense variants with a loss-of-function effect on the sodium channel. A third group, smaller than the other two, with intellectual disability and autism and no epilepsy with truncations and loss-of-function effect on the sodium channel [2].

In a retrospective review of 12 pediatric patients with SCN2A pathogenic variants, Howell et al describes a wide phenotype of severity of epilepsy and developmental outcome. Median seizure onset was 2 days of life, ranging from 1 day 17 years of age. Seizures were often frequent, occurring several times an hour in $75 \%$ of patients. Seizure semiology varied, including focal seizures asymmetric tonic seizures, hemiclonic seizures, asymmetric bilateral clonic seizures, epileptic spasms, and hypomotor seizures with autonomic features. Seizures were mostly brief, but often occurred in clusters. All patients had developmental plateau or regression in periods with high seizure burden. 83\% of patients had movement disorders, $92 \%$ had axial hypotonia, $67 \%$ had spasticity, $67 \%$ had early handedness, and $16 \%$ had abnormal gait. $63 \%$ of patients treated with phenytoin exhibited a significant improvement in seizure frequency. 3 patients in this small review experienced sudden unexplained death in epilepsy (SUDEP) [4].

Response to treatment is heterogeneous, and dependent on severity of phenotype, age of onset of seizures, and effect on the 
sodium channel function. Patients with benign familial neonatalinfantile seizures often have a good response to antiseizure medications, though they can be medication-resistant, especially in cases with de novo mutations [5]. In patients with epileptic encephalopathy, seizures are medication-resistant in 40-100\% of patients [5]. There appears to be a heterogeneous response to voltage-gated sodium channel blockers, with patients who have onset of epilepsy younger than 3 months of age being more likely to be responders than patients with a later onset of epilepsy [2].

In summary, pathogenic variants in the SCN2A gene lead to a wide variety of developmental, cognitive, and epilepsy outcomes. Finding pathogenic variants in patients with epilepsy and evidence of epileptic encephalopathies can have wide ranging impact on prognosis and treatment and can help patients and families get access to support and research in patient advocacy groups such as Familie SCN2A foundation (https://www.scn2a.org).

\section{References}

1. Oliva M, Berkovic SF, Petrou S (212) Sodium channels and the neurobiology of epilepsy. Epilepsia 53(11): 1849-1859.

2. Wolff M, Johannesen KM, Hedrich UBS, Masnada S, Rubboli G, et al. (2017) Genetic and phenotypic heterogeneity suggest therapeutic implications in SCN2A-related disorders. Brain 140(5): 1316-1336.

3. Lauxmann S, Verbeek NE, Liu Y, Zaichuk M, Mueller S, et al. (2018) Relationship of electrophysiological dysfunction and clinical severity in SCN2A-related epilepsies. Human Mutation 39(12): 1942-1956.

4. Howell KB, McMahon JM, Carvill GL, Tambunan D, Mackay MT, et al. (2015) SCN2A encephalopathy A major cause of epilepsy of infancy with migrating focal seizures. Neurology 85(11): 958-966.

5. Wolff M, Brunklaus A, Zuberi SM (2019) Phenotypic spectrum and genetics of SCN2A-related disorders, treatment options, and outcomes in epilepsy and beyond. Epilepsia 60(S3): S59-S67.

\section{Your next submission with Juniper Publishers} will reach you the below assets

- Quality Editorial service

- Swift Peer Review

- Reprints availability

- E-prints Service

- Manuscript Podcast for convenient understanding

- Global attainment for your research

- Manuscript accessibility in different formats ( Pdf, E-pub, Full Text, Audio)

- Unceasing customer service

Track the below URL for one-step submission https://juniperpublishers.com/online-submission.php 